\title{
PHENOLIC COMPOUNDS AND ANTIOXIDANT ACTIVITIES OF MACERATED ALPINIA GALANGA STEMS AND LEAVES
}

\author{
Masrina Mohd Nadzir, Farhana Nazira Idris, and Chin Jing Yi \\ School of Chemical Engineering, Engineering Campus, Universiti Sains Malaysia, Penang, Malaysia, \\ Tel: +604-5996427, e-mail: chmasrina@usm.my
}

Received Date: July 12, 2019; Revised Date: October 22, 2019; Acceptance Date: December 20, 2019

\begin{abstract}
Alpinia galanga (A. galanga) is a popular culinary ingredient as well as medicinal herb commonly found in Southeast Asia. Compared to the rhizome of A. galanga, the leaves and stems are always being discarded as waste. In this research, active compounds from the stem and leaves of this plant were extracted using maceration technique with ethanol as solvent at a liquid-solid ratio of $20 \mathrm{ml} / \mathrm{g}$. The influence of maceration time and maceration temperature on total phenolic content (TPC) and antioxidant activities of extract were studied using Folin-Ciocalteu assay and DPPH radical scavenging assay, respectively. The maceration time was from 1 to $5 \mathrm{hr}$ and the maceration temperature was examined from $40{ }^{\circ} \mathrm{C}$ to $70{ }^{\circ} \mathrm{C}$. Crude extract yield for stems and leaves obtained for all parameters of the maceration process was $>11 \%$. The highest TPC for leaves was obtained at $1 \mathrm{hr}(0.038 \pm 0.02 \mathrm{mg} \mathrm{GAE} / \mathrm{mg} \mathrm{DW})$ and stems at $4 \mathrm{hr}(0.024 \pm 0.01 \mathrm{mg} \mathrm{GAE} / \mathrm{mg} \mathrm{DW})$. Similar trend was also observed for antioxidant activity where the highest antioxidant activity obtained for leaves was at $1 \mathrm{hr}\left(\mathrm{IC}_{50}=0.136 \pm 0.01 \mathrm{mg} / \mathrm{ml}\right)$ and for stems was at $4 \mathrm{hr}\left(\mathrm{IC}_{50}=0.320 \pm 0.07 \mathrm{mg} / \mathrm{ml}\right)$. Maceration time however, has no significant influence on TPC $(p>0.09)$ and antioxidant activity ( $p>0.16$ ) of A. galanga. In terms of temperature, the highest TPC was recorded at $70{ }^{\circ} \mathrm{C}$ for both leaves $(0.034 \pm 0.003 \mathrm{mg} \mathrm{GAE} / \mathrm{mg} \mathrm{DW})$ and stems $(0.019 \pm 0.005 \mathrm{mg} \mathrm{GAE} / \mathrm{mg} \mathrm{DW})$, while the highest antioxidant activity was from sample extracted at $40{ }^{\circ} \mathrm{C}$ for both leaves $\left(\mathrm{IC}_{50}=0.076 \pm 0.05\right.$ $\mathrm{mg} / \mathrm{ml})$ and stems $\left(\mathrm{IC}_{50}=0.454 \pm 0.16 \mathrm{mg} / \mathrm{ml}\right)$. The best maceration conditions, considering from the antioxidant activity, for both leaves and stems of $A$. galanga were concluded at $1 \mathrm{hr}$ and $40{ }^{\circ} \mathrm{C}$ in the viewpoint of both extract quality, energy and cost efficiency.
\end{abstract}

Keywords: Alpinia galanga, Antioxidant activities, Maceration, Phenolic compound

\section{Introduction}

The World Health Organization (WHO) states that medicinal plants are being used as remedies by up to $95 \%$ of the populations in developing countries [1]. Furthermore, the global herbal drug market forecasted to reach US \$5 trillion by the year 2050 [2], hence research effort regarding herbal drugs needs to be intensified considering its great future prospect.

Phenolic compounds from plants could be extracted using conventional techniques such as maceration and Soxhlet extraction or by using modern ones like ultrasound-assisted extraction, microwave assisted extraction, and supercritical fluid extraction. The choice of extraction techniques typically depends on the feasibility of the technique, availability of extraction equipment and convenience. Although modern extraction techniques offer high extraction yield and reduction in extraction time, conventional techniques are still relevant due to the ease of use and cheaper experimental setup. In the extraction technique used in this study, maceration time and maceration temperature are among the two factors that influence the extraction of phenolic compounds from plants. This is because sufficient time is 
required for the compounds to migrate from plant sample to extraction solvent while an increment of temperature during extraction increase mass transfer rate and diffusion coefficient between plant compounds and solvent.

Of many edible native plants in Malaysia, considerable attention is given to Alpinia galanga (A. galanga), known locally as lengkuas. It is a perennial herb found commonly throughout India as well as in countries like Thailand, Indonesia, and China [3]. This plant not only grown in commercial scale but also could be easily found in kitchen gardens as it is one of the common ingredients of Southeast Asian cooking. Belonging to the Zingiberaceae family, $A$. galanga exhibits a huge range of biological activities including antitumor, antibacterial and antiulcer $[4,5]$. Furthermore, this plant was also reported to contain antioxidant, the substance that is able to suppress radical chain reactions [6]. Its flower has three-fold higher total phenols content than rhizome and contains 1'-acetoxyeugenol acetate as the major compound [7]. Chouni et al. [8] states that the leaves and flowers of A. galanga showed the highest chelating and $\beta$ carotene bleaching ability, thus suspecting potential dietary source of natural antioxidant from flower and leaves.

Compared to the rhizomes which are prevalently used as spice in cooking, the A. galanga leaves and stems often being discarded as waste. Thus, both A. galanga leaves and stems were examined in this study with varying maceration time and temperature to evaluate whether considerable amount of phenolic compounds are present in them, hence recognizing their medicinal value, which would turn these plant's parts into valuable products.

\section{Materials and Methods}

\section{Preparation of Plant Sample}

Fresh discarded A. galanga leaves and stems were collected from Parit Nibong, Kedah, Malaysia. Plant samples were washed under running tap water to remove dirt and contaminants. Initial weight of the leaves and stems were measured separately before drying in an oven at 80 ${ }^{\circ} \mathrm{C}$ until the weight of samples remained constant at $5 \%$ moisture content. This was followed by grinding of dried sample into powder and sieving through stainless steel mesh sieve with 710 $\mu \mathrm{m}$ opening to obtain samples of $<710 \mu \mathrm{m}$. The raw powdered samples were stored at $4{ }^{\circ} \mathrm{C}$ in air-tight containers until further use.

\section{Extraction of Alpinia Galanga}

The influence of maceration time (1, 2, 3, 4, and $5 \mathrm{hr})$ on crude extract yield and extract quality was studied. Temperature and liquid-solid ratio of samples at respective extraction time were kept constant at $60^{\circ} \mathrm{C}$ and $20 \mathrm{ml} / \mathrm{g}$. Powdered leaves was macerated in ethanol in a $200 \mathrm{ml}$ beaker at the aforementioned parameters accompanied with stirring at $125 \mathrm{rpm}$ using magnetic stirrer.

After completion of extraction, powdered leaves were separated from solvent using a muslin cloth followed by filtering by filter paper (Whatman no.1). Rotary evaporator was then used to concentrate the extract at vacuum pressure of 170 mbar, rotating speed of $60 \mathrm{rpm}$, and water bath temperature $60{ }^{\circ} \mathrm{C}$. The concentrated extract was then removed from the evaporation flask wall using a spatula and the crude extract yield $(\%)$ was calculated as the weight $(\mathrm{g})$ of crude extracts obtained from weight $(\mathrm{g})$ of raw materials. Crude extract was then kept in a sample bottle at $4{ }^{\circ} \mathrm{C}$ for further analysis. The extract quality was then investigated and the best extraction time (1 hr) was applied for the subsequent study with varying maceration temperature $\left(40,50,60\right.$ and $70{ }^{\circ} \mathrm{C}$ ), while maintaining the liquid-solid ratio of samples at $20 \mathrm{ml} / \mathrm{g}$. The extraction process was then repeated using powdered stem samples. 


\section{Determination of Extract's Phenolic Content}

The total phenolic content (TPC) of A. galanga extract was examined using Folin-Ciocalteu reagent (FCR) according to the method of Dolatabadi et al. [9] with slight modifications. Initially, FCR solution (the reference solution), sodium carbonate $\left(\mathrm{Na}_{2} \mathrm{CO}_{3}\right)$ solution at $7.5 \%$ $(\mathrm{w} / \mathrm{v})$, standard gallic acid solution $(0.0078125,0.015625,0.03125,0.0625$ and 0.125 $\mathrm{mg} / \mathrm{ml}$ ) and blank solution were prepared prior to the test. The reference solution was prepared by diluting FCR with distilled water at ten times dilution factor. The blank solution was prepared by mixing $5 \mathrm{ml}$ of FCR solution, $1 \mathrm{ml}$ of ethanol and $4 \mathrm{ml}$ of $7.5 \%(\mathrm{w} / \mathrm{v})$ $\mathrm{Na}_{2} \mathrm{CO}_{3}$ solution in a test tube. The extract of $A$. galanga was diluted in ethanol to give a concentration of $1 \mathrm{mg} / \mathrm{ml}$. The diluted plant extract $(1 \mathrm{ml})$ and standard gallic acid solutions of different concentrations were then pipetted into respective test tubes, followed by addition of $5 \mathrm{ml} \mathrm{FCR}$ solution and $5 \mathrm{ml} \mathrm{Na} \mathrm{CO}_{3}$ solution $(7.5 \%$ (w/v)). The mixtures were incubated for 20 minutes at room temperature before absorbance of the mixtures was measured using UV-Vis spectrophotometer (Cary $60 \mathrm{UV}$-Vis, Agilent Technologies) at $760 \mathrm{~nm}$. Total phenolic content was expressed as milligram of gallic acid per gram plant extract and determined using Equation (1):

$$
A=\frac{c \times V}{m}
$$

Where, $A$ is the total phenolic content (mg GAE/mg plant extract), $c$ is the concentration determined from standard gallic acid calibration curve $(\mathrm{mg} / \mathrm{ml}), V$ is the volume of extract solution ( $\mathrm{ml})$, and $m$ is the mass of extract used $(\mathrm{g})$.

\section{Measurement of Antioxidant Activity}

In this study, 1,1-diphenyl-2-picrylhydrazyl (DPPH) scavenging assay was used to determine antioxidant activity of crude extract [9]. The control solution (0.1 mM DPPH solution) was prepared by adding $4 \mathrm{mg}$ DPPH in $100 \mathrm{ml}$ ethanol. The standard solution was prepared by adding $1 \mathrm{mg}$ ascorbic acid in $10 \mathrm{ml}$ distilled water, rendering it a 0.1 $\mathrm{mg} / \mathrm{ml}$ concentration. This aqueous ascorbic acid was then diluted to $0.0125,0.00625$, 0.003125 and $0.0015625 \mathrm{mg} / \mathrm{ml}$. Blank solution contained merely ethanol. Then, the different concentrations of standard ascorbic acid solution $(2 \mathrm{ml})$ were pipetted into respective test tubes. This was followed by the addition of $3 \mathrm{ml}$ of DPPH solution and incubation of mixtures in the dark for 30 minutes. The absorbance of the mixtures was measured using UV-Vis spectrophotometer at $517 \mathrm{~nm}$ against blank solution. These steps were repeated by replacing ascorbic acid with crude extract of A. galanga leaves and stems, in which the extract solutions were prepared in serial concentrations for leaves $(0.4,0.2,0.1,0.05$ and $0.025,0.00625 \mathrm{mg} / \mathrm{ml})$ and for stem $(1.0,0.5,0.25,0.125$, $0.0625 \mathrm{mg} / \mathrm{ml}$ ) on the basis that $1 \mathrm{mg} / \mathrm{ml}$ concentration of stock solution consists $1 \mathrm{mg}$ plant extract and $1 \mathrm{ml}$ ethanol. Inhibition activity (I\%) was calculated using Equation 2 and a graph of I\% against concentration of either crude plant extract or standard ascorbic acid was plotted to determine $\mathrm{IC}_{50}$.

$$
I \%=\frac{A_{C}-A_{E}}{A_{C}} \times 100 \%
$$

Here, $A_{C}$ is the absorbance of control and $A_{E}$ is the absorbance of extract or standard solutions. 


\section{Statistical Analysis}

The results are expressed as mean \pm standard deviation of triplicate assays and analysed by Microsoft Excel 2010. Student's $t$-test was used to determine statistically different values at a significance level of $p \leq 0.05$. Pearson correlations between variables were established using MINITAB software (version 19).

\section{Results and Discussion}

\section{Effect of Extraction Time and Temperature on Yield of Crude Extract}

The influences of time and temperature on the yield of crude extract are shown in Figure 1. With respect to maceration time, the highest yield of crude leave's extract $(13.62 \%)$ was obtained at $4 \mathrm{hr}$ whereas for crude stem's extract, the highest yield (13.22\%) was obtained at $2 \mathrm{hr}$. In the case of maceration temperature, the highest yield for leave's extract (15.49\%) and stem's extract $\left(13.44 \%\right.$ ) were obtained at $60{ }^{\circ} \mathrm{C}$ and $70{ }^{\circ} \mathrm{C}$, respectively. Both parameters were found to have no significant influence $(p>0.09)$ on the crude extract yield of stems and leaves.

(A)

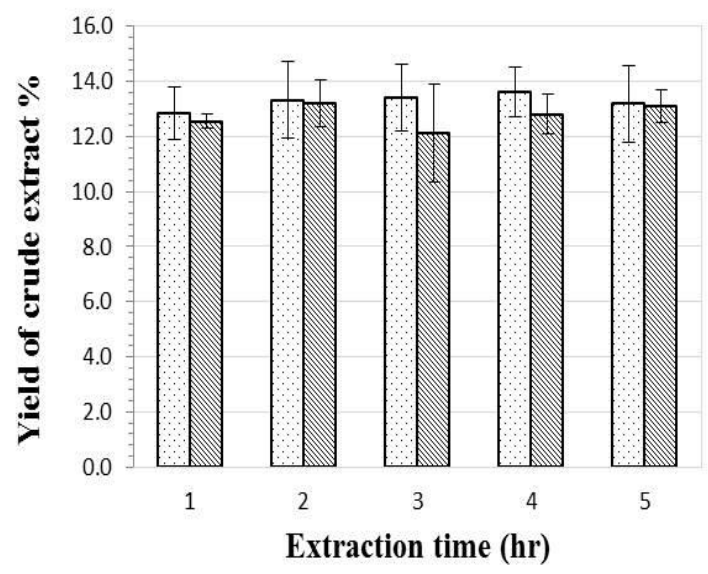

(B)

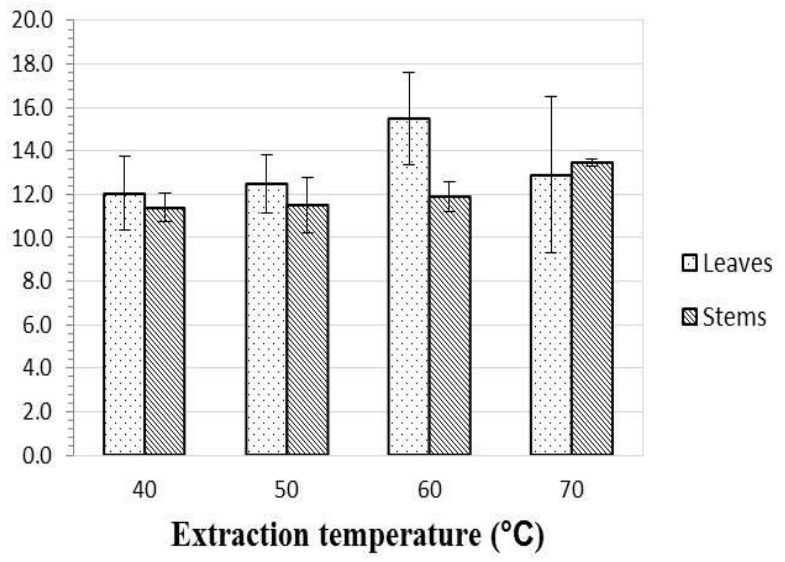

Figure 1. Influence of maceration time (A) and temperature (B) on the extraction yield $(\%)$

Similar findings on non-significant influence of maceration time and temperature on the extraction yield has been reported by Andriyani et al. [10] on the extraction of Zingiber officinale at various time (30, 60 and 90 minutes) and temperature $\left(50,70,90{ }^{\circ} \mathrm{C}\right)$. This shows that in this study, final equilibrium nearly attained between the active compound concentrations in the solid matrix and bulk solvent [11] after $1 \mathrm{hr}$ extraction time even at elevated temperature.

\section{Total Phenolic Content of Leaves and Stems Extracts}

The TPC of each sample was obtained through interpolation from standard gallic acid curve. Although the TPC of leaves and stems were the highest for sample extracted for $1 \mathrm{hr}(0.038$ $\pm 0.03 \mathrm{mg} \mathrm{GAE} / \mathrm{mg} \mathrm{DW})$ and $4 \mathrm{hr}(0.024 \pm 0.01 \mathrm{mg} \mathrm{GAE} / \mathrm{mg} \mathrm{DW})$, respectively, the results in Figure 2 indicate that the maceration time has little or no influence on the TPC of leaves' extracts $(p>0.99)$ and stem's extracts $(p>0.20)$. 


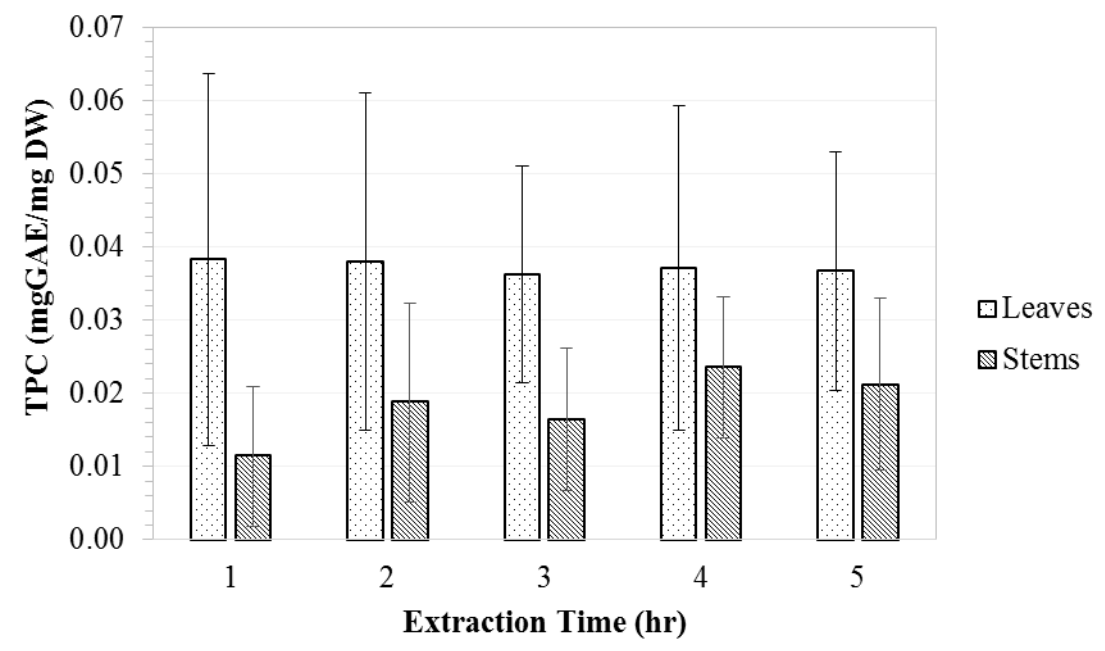

Figure 2. Influence of maceration time on phenolic content of A. galanga extracts

Typically, TPC tends to increase parallel to maceration time until a certain peak because solubility of compound in samples was proportional to the time spent to reach saturation point [12]. Nevertheless, prolonged extraction time could have deteriorating effect on the phenolic compounds due to oxidation. Experimental work from Juntachote et al. [13] showed that effect of extraction time was insignificant towards TPC of lemon grass, galangal and rosemary. This result was in line with findings from Kwon et al. [14] where TPC of ginseng extract was not influenced by the time required for extraction.

The maceration temperature was found to have little influence on the TPC of extracts (Figure 3). Although there was an increasing trend of TPC with temperature increment, the differences in TPC with increasing temperature was insignificant for both leaves $(p>0.16)$ and stems $(p>0.09)$. Since phenolic compounds are strongly bound to cell wall hemicellulose, alteration to the cell wall polysaccharides through heating at temperature higher than $70^{\circ} \mathrm{C}$ or pre-treating A. galanga samples to degrade the cell wall prior to maceration may lead to increased extractability of phenolic compounds.

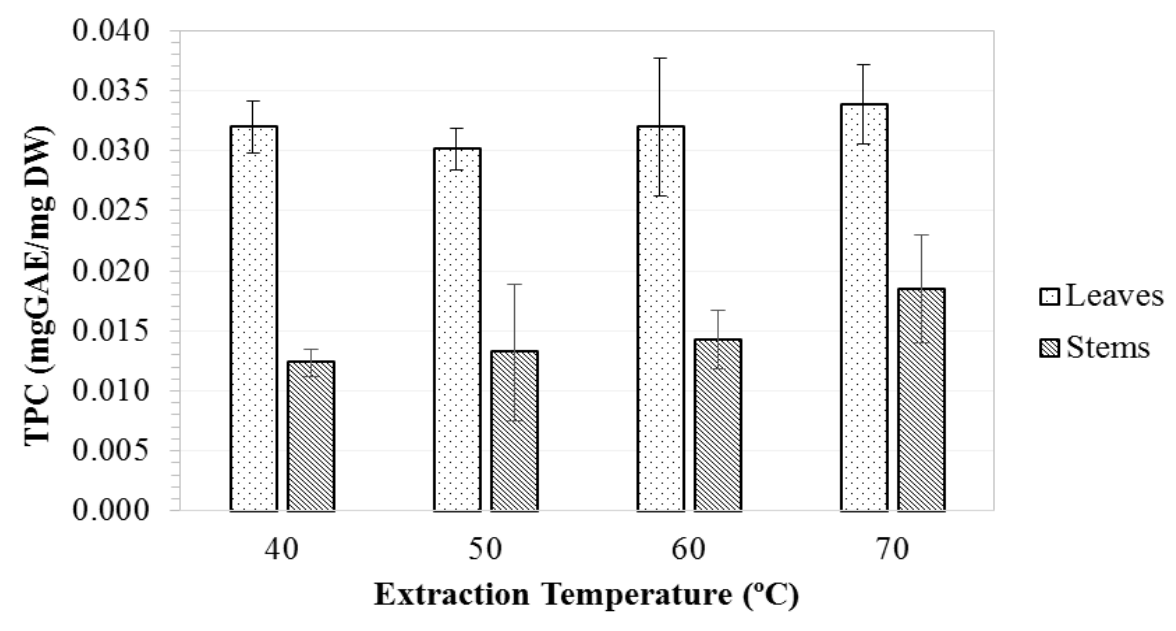

Figure 3. Effect of maceration temperature on TPC of A. galanga leaves and stems 


\section{Radical Scavenging Activity of Leaves and Stems Extracts}

Antioxidant activity of $A$. galanga was studied based on the $\mathrm{IC}_{50}$ value where a lower $\mathrm{IC}_{50}$ indicates a higher antioxidant activity of the compound and vice versa [15]. The effect of maceration time on leaves and stems of A. galanga antioxidant activity are shown in Figure 4. Based on the result, the lowest $\mathrm{IC}_{50}$ value in leaves, which indicates the best antioxidant capability, was recorded at $1 \mathrm{hr}(0.136 \pm 0.01 \mathrm{mg} / \mathrm{ml})$, followed by $3 \mathrm{hr}(0.144 \pm$ $0.03 \mathrm{mg} / \mathrm{ml})$ and $5 \mathrm{hr}(0.154 \pm 0.05 \mathrm{mg} / \mathrm{ml})$. No significant trend was observed from the results and it can be seen that maceration time has little effect on antioxidant activity of leave's extracts $(p>0.16)$. A non-significant effect of maceration time on antioxidant activity was also observed for $A$. galanga stem $(p>0.26)$. The lowest $\mathrm{IC}_{50}$ value recorded for stem's extract was at the maceration time of $4 \mathrm{hr}$ while the highest $\mathrm{IC}_{50}$ value was observed at $1 \mathrm{hr}$ $(0.813 \pm 0.74 \mathrm{mg} / \mathrm{ml})$.

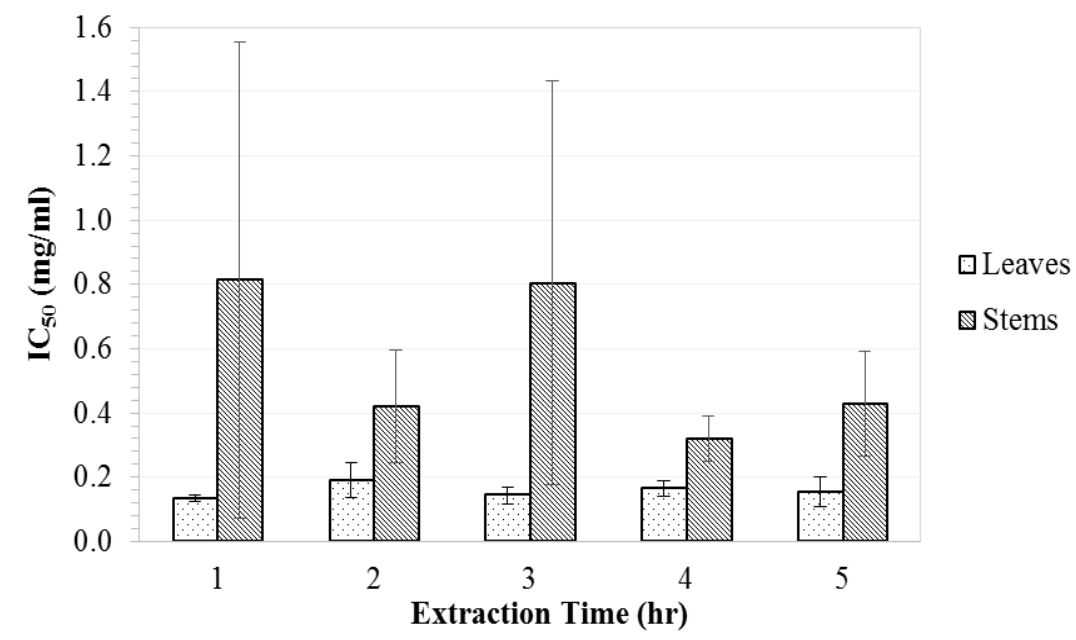

Figure 4. Influence of maceration time on A. galanga extract's antioxidant activity

Linear relationship between antioxidant activity and extraction time has been reported for the maceration of Sargassum sp. in ethanol for 6 to $24 \mathrm{hr}$, whereby the antioxidant activity was the highest for extract of sample macerated for $24 \mathrm{hr}$ [12]. However, prolonged extraction time might also compromise the capability of antioxidant, as observed by Chew et al. [16] where the antioxidant activity of extracts of Orthosiphon stamineus (O. stamineus) macerated in ethanol decreased significantly when the extraction time exceeded $4 \mathrm{hr}$ due to possible oxidation of the extract.

There are also studies reported that extraction time has no significant effect on antioxidant activity, which coincide with findings from results shown in Figure 4. Hashim et al. [17] found that radical scavenging activity, which indicates the antioxidant activity, has no significant increase when comparing extracts of $O$. stamineus macerated for 4 $\mathrm{hr}$ and $8 \mathrm{hr}$. Moreover, similar result was observed when Herrero et al. [18] conducted experiment on rosemary to study the influence of extraction time on plant's antioxidant activity using pressurized liquid extraction technique in various solvents. The experiment results showed that extraction time had minimal influence on the antioxidant activity of rosemary.

It can be seen from Figure 5 that $\mathrm{IC}_{50}$ value of extract from leaves was the lowest at $40{ }^{\circ} \mathrm{C}(0.076 \pm 0.05 \mathrm{mg} / \mathrm{ml})$ and the highest at $70{ }^{\circ} \mathrm{C}(0.146 \pm 0.02 \mathrm{mg} / \mathrm{ml})$. However, the antioxidant activity of $A$. galanga stems exhibited different trend from the leaves. At similar 
extraction temperature range, stem extract's antioxidant activity first decreased when maceration temperature was raised from $40{ }^{\circ} \mathrm{C}\left(\mathrm{IC}_{50}=0.454 \pm 0.16 \mathrm{mg} / \mathrm{ml}\right)$ to $60{ }^{\circ} \mathrm{C}\left(\mathrm{IC}_{50}=\right.$ $0.734 \pm 0.28 \mathrm{mg} / \mathrm{ml})$. The antioxidant activity then increased upon further heating of sample at $70{ }^{\circ} \mathrm{C}\left(\mathrm{IC}_{50}=0.502 \pm 0.13 \mathrm{mg} / \mathrm{ml}\right)$.

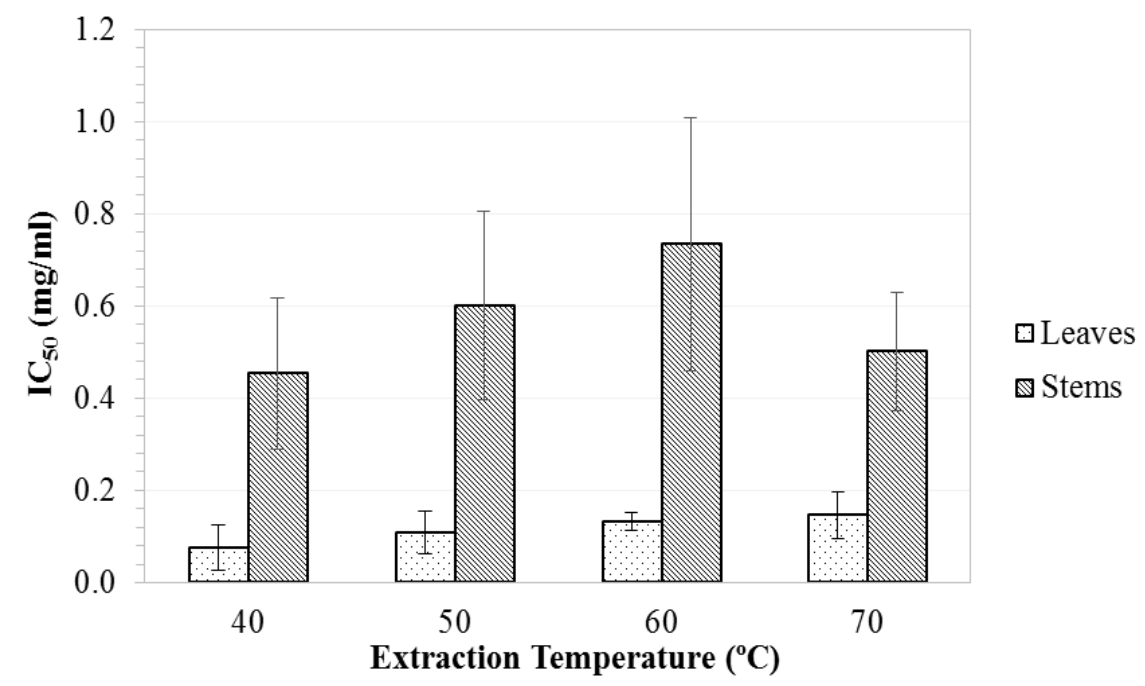

Figure 5. Influence of maceration temperature on antioxidant activity of A. galanga extracts

The result obtained by $A$. galanga leaves is aligned with study conducted by Bahrin et al. [19] on Ficus carica leaves in which temperature higher than $50{ }^{\circ} \mathrm{C}$ will cause thermal degradation of phenolic compounds which leads to decreased in antioxidant activity as phenolic compounds were oxidized and hydrolysed at high temperature. However, it is important to take note that a slightly higher extraction temperature could improve mass transfer rate and solubility between compound in plant extract and solvent. Moreover, different polyphenol antioxidants are being extracted at both low and high temperature. The result of antioxidant activity of A. galanga stems points out that the stem of this plant contains high proportions of thermo labile and thermo stable components. Similar findings was reported on the extraction of Guiera senegalensis [20], where the best antioxidant activity was achieved from sample extracted at low temperature $\left(40^{\circ} \mathrm{C}\right)$ and high temperature $\left(70\right.$ to $85^{\circ} \mathrm{C}$ ), whereas samples extracted in between these temperature points have lower antioxidant activities.

To further understand the interrelationship between antioxidant capacity and the TPC, the correlations under different extraction conditions were analysed and presented in Table 1. Under the influence of maceration time, a strong significant $(p<0.05)$ negative correlation was observed between TPC and DPPH $(r=-0.869)$ for leave's extract. On the other hand, a medium non-significant negative correlation was observed for stem's extract. As for the influence of extraction temperature, small non-significant and strong nonsignificant negative correlations between TPC and DPPH were observed for leave's extract and stem's extract, respectively. This shows that the antioxidant activity in A. galanga extract is not exclusively governed by phenolic compound and could also be contributed by proteins and minerals that exist in this plant [21]. Thus, although high TPC was obtained at example $60{ }^{\circ} \mathrm{C}$, the other compounds that contributed to the antioxidant activity might have degraded when extracted at that parameter. 
Table 1. Correlation Coefficient ( $r$ ) between Activities of Antioxidant and TPC under the Influence of Plant's Component, Maceration Time and Maceration Temperature

\begin{tabular}{lll}
\hline Source of Extract & Leaves & Stems \\
\cline { 1 - 1 } Extraction Parameter & & \\
Time & $-0.869^{*}$ & -0.33 \\
Temperature & -0.166 & -0.557 \\
\hline
\end{tabular}

${ }^{*} p<0.05$

\section{Conclusions}

In the current study, the crude extract yield, TPC and antioxidant activity of extracts obtained at $1 \mathrm{hr}$ and at $40{ }^{\circ} \mathrm{C}$ were not significantly different from the ones obtained at longer maceration time or at higher maceration temperature. From economic point of view, the best maceration conditions determined based on antioxidant capability are at maceration time of $1 \mathrm{hr}$ and maceration temperature of $40^{\circ} \mathrm{C}$ for both $A$. galanga leaves and stems, with $\mathrm{IC}_{50}$ at $0.076 \pm 0.05 \mathrm{mg} / \mathrm{ml}$ and $0.454 \pm 0.16 \mathrm{mg} / \mathrm{ml}$, respectively. The negative correlations between the antioxidant activity and TPC of extracts indicate that phenolic compounds are not the sole contributor to the antioxidant capacity. The results from the current study are important to determine the range of factors that has a significant effect on the recovery of active compounds. The main challenge faced in the current study was obtaining standardized results due to the heterogeneity of the plant samples in terms of plant age or plant development. Thus, screening of raw materials is a necessary step when exploiting agriculture waste in order to obtain high quality standardized extracts.

\section{References}

[1] M.M. Robinson, and X. Zhang, "Traditional medicines: Global situation, issues and challenges," In The World Medicines Situation 2011, $3^{\text {rd }}$ Edition, WHO Press, Geneva, Switzerland, pp. 1-14, 2011.

[2] T. Citarasu, "Herbal biomedicines: A new opportunity for aquaculture industry," Aquaculture International, Vol. 18, No. 3, pp. 403-414, 2010.

[3] A. Chudiwal, D. Jain, and R. Somani, "Alpinia galanga Willd.-An overview on phytopharmacological properties," Indian Journal of Natural Products and Resources, Vol. 1, No. 2, pp. 143-149, 2010.

[4] R. Datta, A. Kaur, I. Saraf, I.P. Singh, and S. Kaur, "Effect of crude extracts and purified compounds of Alpinia galanga on nutritional physiology of a polyphagous lepidopteran pest, Spodoptera litura (Fabricius)," Ecotoxicology and Environmental Safety, Vol. 168, pp. 324-329, 2019.

[5] X.-L. Zhu, M.-H. Yang, J.-G. Luo, X.-F. Huang, and L.-Y. Kong, "A new phenylpropanoid from Alpinia galangal," Chinese Journal of Natural Medicines, Vol. 7, No. 1, pp. 19-20, 2009.

[6] C. Chansriniyom, P. Bunwatcharaphansakun, W. Eaknai, N. Nalinratana, A. Ratanawong, M. Khongkow, and R. Luechapudiporn, "A synergistic combination of Phyllanthus emblica and Alpinia galanga against $\mathrm{H}_{2} \mathrm{O}_{2}$-induced oxidative stress and lipid peroxidation in human ECV304 cells," Journal of Functional Foods, Vol. 43, pp. 44-54, 2018.

[7] X. Tang, C. Xu, Y. Yagiz, A. Simonne, and M.R. Marshall, "Phytochemical profiles, and antimicrobial and antioxidant activities of greater galangal [Alpinia galanga (Linn.) Swartz.] flowers," Food Chemistry, Vol. 255, pp. 300-308, 2018.

[8] A. Chouni, and S. Paul, "A review on phytochemical and pharmacological potential of Alpinia galanga," Pharmacognosy Journal, Vol. 10, No. 1, pp. 9-15, 2018. 
[9] K.S.M. Dolatabadi, G. Dehghan, S. Hosseini, and A.J. Esfahlan, "Effect of five year storage on total phenolic content and antioxidant capacity of almond (Amygdalus communisL.) hull and shell from different genotypes," Avicenna Journal Phytomedicine, Vol. 5, pp. 26-33, 2015.

[10] R. Andriyani, W. Kosasih, D.R. Ningrum, and S. Pudjiraharti, "Effect of temperature, time, and milling process on yield, flavonoid, and total phenolic content of Zingiber officinale water extract," In: IOP Conference Series: Earth and Environmental Science, Vol. 60, IOP Publishing, pp. 1-5, 2017.

[11] C.H. Chan, R. Yusoff, and G.C. Ngoh, "Modeling and kinetics study of conventional and assisted batch solvent extraction," Chemical Engineering Research and Design, Vol. 92, pp. 1169-1186, 2014.

[12] B.B. Sasmito, S. Wijana, and H.S. Kumalaningsih, "Effect of crystallization and maceration time on antioxidant activity of ethanolic extract from brown algae Sargassum sp.," International Journal of Advanced Research, Vol. 2, pp. 861-867, 2014.

[13] T. Juntachote, E. Berghofer, F. Bauer, and S. Siebenhandl, "The application of response surface methodology to the production of phenolic extracts of lemon grass, galangal, holy basil and rosemary," International Journal of Food Science \& Technology, Vol. 41, pp. 121-133, 2006.

[14] J.-H. Kwon, J.M. Bélanger, and J.J. Paré, "Optimization of microwave-assisted extraction (MAP) for ginseng components by response surface methodology," Journal of Agricultural and Food Chemistry, Vol. 51, pp. 1807-1810, 2003.

[15] Q.D. Do, A.E. Angkawijaya, P.L. Tran-Nguyen, L.H. Huynh, F.E. Soetaredjo, S. Ismadji, and Y.-H. Ju, "Effect of extraction solvent on total phenol content, total flavonoid content, and antioxidant activity of Limnophila aromatic," Journal of Food and Drug Analysis, Vol. 22, pp. 296-302, 2014.

[16] K. Chew, M. Khoo, S. Ng, Y. Thoo, W.W. Aida, and C. Ho, "Effect of ethanol concentration, extraction time and extraction temperature on the recovery of phenolic compounds and antioxidant capacity of Orthosiphon stamineus extracts," International Food Research Journal, Vol. 18, pp. 1427-1435, 2011.

[17] N. Hashim, A.R. Shaari, A.S. Mamat, and S. Ahmad, "Effect of differences methanol concentration and extraction time on the antioxidant capacity, phenolics content and bioactive constituents of Orthosiphon Stamineus extracts," MATEC Web of Conferences, EDP Sciences, pp. 1-7, 2016.

[18] M. Herrero, M. Plaza, A. Cifuentes, and E. Ibáñez, "Green processes for the extraction of bioactives from Rosemary: Chemical and functional characterization via ultraperformance liquid chromatography-tandem mass spectrometry and in-vitro assays," Journal of Chromatography A, Vol. 1217, pp. 2512-2520, 2010.

[19] N. Bahrin, N. Muhammad, N. Abdullah, B.H.A. Talip, S. Jusoh, and S.W. Theng, "Effect of processing temperature on antioxidant activity of Ficus carica leaves extract," Journal of Science and Technology, Vol. 10, No. 2, pp. 99-103, 2018.

[20] R. Go, S.S. Kankara, M. Mustafa, H.M. Ibrahim, and R. Nulit, "Effect of drying methods, solid-solvent ratio, extraction time and extraction temperature on phenolic antioxidants and antioxidant activity of Guiera senegalensis JF Gmel (Combretaceae) leaves water extract," International Journal of Medical Research and Review, Vol. 2, pp. 1378-1392, 2014.

[21] A. Rachkeeree, K. Kantadoung, R. Suksathan, R. Puangpradab, P.A. Page, and S.R. Sommano, "Nutritional compositions and phytochemical properties of the edible flowers from selected Zingiberaceae found in Thailand," Frontiers in Nutrition, Vol. 5, pp. 1-10, 2018. 